\section{Effect of a commercial steam-vacuuming treatment implemented after slaughtering for the decontamination of cattle carcasses}

\author{
Mirjam Hochreutener, Claudio Zweifel, \\ Sabrina Corti, Roger Stephan \\ Institute for Food Safety and Hygiene, \\ Vetsuisse Faculty University of Zurich, \\ Zurich, Switzerland
}

\begin{abstract}
To assess the antimicrobial effect of a commercial steam-vacuuming system newly implemented after slaughtering, 105 cattle carcasses were examined for total viable counts (TVC) at four different areas. Before steam vacuuming, mean TVC of the excision samples were comparable at the perineal area and brisket (3.0-3.1 log CFU $\left.\mathrm{cm}^{-2}\right)$ or the hind leg and shoulder (2.6-2.7

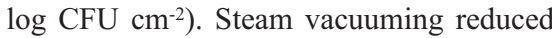
mean TVC by $0.9,0.7,0.6$, and $0.4 \log$ CFU $\mathrm{cm}^{-2}$ at the perineal area, hind leg, shoulder, and brisket, respectively. With regard to the distribution of counts, steam vacuuming increased the proportion of TVC results $<3.0 \log$ CFU $\mathrm{cm}^{-2}$ from 74.8\% (62.9$87.6 \%$ at carcass areas) to $86.7 \%$ (71.4$97.1 \%$ at carcass areas). Thus, steam vacuuming after slaughtering might be useful for the reduction of contamination in designated carcass areas, but the effect must not be overestimated and decontamination treatments always must be seen part of an integral food safety system.
\end{abstract}

\section{Introduction}

To ensure food safety at slaughter, additional measures to the traditional meat inspection procedures are required, in particular because healthy food-producing animals can be carriers of important bacterial pathogens causing human illness (EFSA/ECDC, 2016). To counter this threat, the focus is currently on preventive systems following the hazard analysis and critical control point (HACCP) principles (Ropkins and Beck, 2000; Sofos, 2008). In view of HACCP-based systems applied at slaughter, intervention systems aimed at reducing bacterial contamination and nonintervention systems aimed at preventing contaminations must be distinguished (Bolton et al., 2001).

Interventions applied at slaughter basically comprise physical, chemical, and bio- logical treatments (Aymerich et al., 2008; Koohmaraie et al., 2005; Loretz et al., 2011; Wheeler et al., 2014). In Europe, carcass interventions with substances other than potable water are tied to strict prescriptions (Hugas and Tsigarida, 2008) and current legislation only permits the use of lactic acid on cattle carcasses [Regulation (EC) No. 103/2013]. Despite the prerequisite of strictly maintaining good slaughter hygiene practices, there is increasing interest in effective decontamination treatments because complete prevention of microbial carcass contamination during slaughter can hardly be warranted. Such interventions should basically be safe, economic, feasible in the production process, widely accepted by the consumers, and they should not change the organoleptic properties of carcasses.

Steam vacuum systems are a combination of physical and thermal treatments. Steam vacuuming is useful for application to small carcass areas that are more likely to be contaminated and for spot treatment of visible contamination (Bolton et al., 2001; Huffman, 2002; Wheeler et al., 2014). Steam vacuuming is implemented at multiple stages in cattle processing and it is also increasingly used in combination with other interventions during slaughter, especially in the US and Canada (Gill, 2009; Greig et al., 2012; Loretz et al., 2011). In the U.S., steam vacuuming is approved by USDAFSIS as a substitute for knife trimming, which is traditionally used to remove localized visible contamination (Gill, 2009). Of the previous studies investigating the microbial effect of steam vacuuming on cattle carcasses, only a few were performed under commercial conditions and examined the effect on naturally contaminated carcasses (Gill and Bryant, 1997; Kochevar et al., 1997). The aim of the present study was to evaluate the effect of a commercial steam-vacuuming system, which was newly implemented after slaughtering, on the microbial contamination of cattle carcasses.

\section{Materials and methods}

\section{Abattoir and slaughter process}

This study was based on investigations carried out during one month (April 2017) in a Swiss cattle abattoir with an annual slaughter capacity of $>20$ million $\mathrm{kg}$. The abattoir processed up to 75 cattle carcasses per h (on average 450 carcasses per day). Slaughter operations were performed on a slaughter line featuring separated wet areas and clean areas (Table 1). After being stunned in a stunning box using a captive
Correspondence: Institute for Food Safety and Hygiene, Vetsuisse Faculty University of Zurich, Winterthurerstrasse 272, 8057 Zurich, Switzerland.

Tel: +41 44635 8651; fax: +41 446358908 . E-mail: roger.stephan@uzh.ch

Key words: Cattle carcasses; Steam vacuuming; Routine operations; Total viable counts; Carcass decontamination.

Conflict of interest: the authors declare no potential conflict of interest.

Acknowledgments: the authors thank the staff of the slaughterhouse involved in this study for the collection of samples and the general assistance.

Received for publication: 23 June 2017. Revision received: 6 August 2017.

Accepted for publication: 24 August 2017

This work is licensed under a Creative Commons Attribution-NonCommercial 4.0 International License (CC BY-NC 4.0).

CC Copyright M. Hochreutener et al., 2017 Licensee PAGEPress, Italy

Italian Journal of Food Safety 2017; 6:6864

doi:10.4081/ijfs.2017.6864

bolt, animals were shackled by the right rear leg and immediately (within $60 \mathrm{~s}$ ) exsanguinated with two different knives (one for the skin and another one for the blood vessel). Before skinning, head and hooves were removed. Skinning operations comprised manually performed pre-skinning and mechanized skinning by an upward-pulling hide puller. Before evisceration, carcasses were moved into separated clean areas. Evisceration involved slitting the belly, removal of the gut and removal of thoracic viscera. Carcasses were then split along the midline from back to front with a splitting saw. After trimming, meat inspection, weighing and grading, carcasses were washed with cold potable water $\left(11^{\circ} \mathrm{C}\right.$ for $20 \mathrm{~s})$ to remove visual debris. The abattoir used a two-stage air chilling process. Carcasses were initially blasted with air at $11 \mathrm{~m} / \mathrm{s}$ and $10^{\circ} \mathrm{C}$ for about $90 \mathrm{~min}$ before entering the chiller $\left(5 \mathrm{~m} / \mathrm{s}\right.$ at $\left.2.0-4.0^{\circ} \mathrm{C}\right)$.

For steam vacuuming, the Vapo-Vac system (Industrade, Strasbourg Cedex, France) was used. The system consisted of a hand-held device with a steam unit (nozzle) and a vacuum unit. The hot spray nozzle (diameter of $8 \times 3 \mathrm{~cm}$ ) delivered steam at $>82^{\circ} \mathrm{C}$ through steam channels to the carcass surface under pressure, while the vacuum unit simultaneously vacuumed the area. The steam (produced from potable water) thereby decontaminated and loosened 
(fecal) material from the carcass surface to facilitate removal by the vacuum unit. Steam vacuuming was performed during routine operations after carcass trimming (but before weighing and grading) by two operators. Steam vacuuming was routinely applied on areas of the hindquarter and the forequarter (breastbone, shoulder, forelegs) of each half carcass. Carcass areas for steam vacuuming were selected based on previous and repeated findings of increased contaminations at these areas.

\section{Collection of samples}

The collection of samples was done during one month (April 2017) at six different sampling days. Sampled cattle were categorized in three age groups: calves $(<6$ months of age), feeder cattle, and cows. In total, 105 carcass halves were investigated at four different carcass areas: two areas of the hindquarter (perineal area, rump) und two areas of the forequarter (brisket, shoulder). For the evaluation of the microbial effect of steam vacuuming, each area (perineal area, rump, brisket, shoulder) of the 105 carcass halves was sampled (i) after trimming just before steam vacuuming (accounting for a total of 420 samples) and (ii) after steam vacuuming (accounting for a total of 420 samples). Samples obtained after steam vacuuming were collected directly adjacent to the location sampled before steam vacuuming. Sampling was performed by excision: a sterile coring punch was used to delimit a tissue area of 5 $\mathrm{cm}^{2}$, which was then excised using a sterile scalpel and forceps. Samples were transported to the laboratory chilled and microbiological examinations were carried out within $24 \mathrm{~h}$ after sampling.

\section{Total viable counts}

Each individual sample (from each carcass area before and after steam vacuuming) was homogenized for $60 \mathrm{~s}$ in $20 \mathrm{ml}$ of $0.85 \%$ saline solution in a stomacher. Suspensions were plated with a spiral plater (Eddy Jet, IUL SA, Barcelona, Spain) onto plate count agar (Oxoid AG, Pratteln, Switzerland) for total viable counts (TVC). Plate count agars were incubated according to ISO 4833-1:2013. Counts were calculated as CFU $\mathrm{cm}^{-2}$ and the detection limit was $80 \mathrm{CFU} \mathrm{cm}^{-2}$.

\section{Data analysis}

Colony counts of individual samples were expressed as $\log \mathrm{CFU} \mathrm{\textrm {cm } ^ { - 2 }}$ and the distribution of counts at different ranges was determined (Table 2). For evaluation of the effect of steam vacuuming at the four different carcass areas (perineal area, hind leg, brisket, shoulder), TVC results from the untreated and the corresponding treated sample were only considered when TVC before steam vacuuming were equal to or above the detection limit of $1.9 \log \mathrm{CFU} \mathrm{cm}^{-}$ 2 (Table 3). For statistical analysis, a value of one-half of the detection limit (40 CFU $\mathrm{cm}^{-2}$ or $1.6 \log \mathrm{CFU} \mathrm{cm} \mathrm{cm}^{-2}$ ) was assigned for any remaining 0 -count plate of samples after steam vacuuming. Values were then compared by reference to mean $(\bar{x})$ values (carcass areas and animal categories). Mean values $(\bar{x})$ of samples differing by $<0.5 \mathrm{log}$

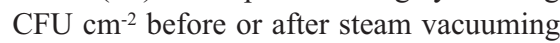
were regarded as similar for practical purposes. Statistical analysis was performed using JMP 13.0 (SAS Institute Inc., Cary, NC, USA). The level of significance was set at $\alpha=0.05$. With regard to carcass areas and animal categories, analysis of variance (ANOVA) and the Tukey HSD test were used to analyze differences in TVC results before and after steam vacuuming.

Table 1. Operations performed in the cattle slaughter process.

\begin{tabular}{ll} 
Location & \\
Wet area & Lairage \\
& Captive bolt stunning; shackling by right rear leg \\
& Sticking and bleeding \\
& Removal of head and hooves \\
& Manual pre-skinning: skin incisions and pre-skinning of rear legs, rump, flank, tail, brisket and forelegs \\
& Skinning by upward-pulling hide puller \\
& Evisceration: brisket sawing, freeing of bung, removal of gut and thoracic viscera \\
Clean area & Carcass splitting with a saw (use of cold water) \\
& Trimming: trimming of butt, rump and brisket; removal of mesenteric fat, diaphragm remnants and spinal cord \\
& Carcass weighing and grading \\
& Steam vacuuming \\
\hline Chiller & Two-stage air chilling process: conventional chilling with preceding blasting \\
\hline
\end{tabular}

Table 2. Distribution of total viable counts results from cattle carcasses before and after steam vacuuming.

\begin{tabular}{|c|c|c|c|c|c|c|c|c|c|c|}
\hline & Sampling area & No. & $\mathrm{Nu}$ & $(\%)$ of & ses wit & Dunts : & different & anges ( & $\log \mathrm{CFU}$ & $\left.\mathrm{cm}^{-2}\right)$ \\
\hline & & of samples & $<1.9 *$ & $1.9-2.5$ & $2.5-3.0$ & $3.0-3.5$ & $3.5-4.0$ & & & $>5.0$ \\
\hline Before steam vacuuming & Perineal area & 105 & $28(26.7)$ & $18(17.1)$ & $20(19.0)$ & $18(17.1)$ & $10(9.5)$ & $6(5.7)$ & $4(3.8)$ & $1(1.0)$ \\
\hline$(n=420)$ & Hind leg & 105 & $53(50.5)$ & $23(21.9)$ & $13(12.4)$ & $8(7.6)$ & $6(5.7)$ & $2(1.9)$ & $0(0)$ & $0(0)$ \\
\hline & Brisket & 105 & $13(12.4)$ & $23(21.9)$ & $31(29.5)$ & $21(20.0)$ & $11(10.5)$ & $2(1.9)$ & $2(1.9)$ & $2(1.9)$ \\
\hline & Shoulder & 105 & $49(46.7)$ & $32(30.5)$ & $11(10.5)$ & $7(6.7)$ & $1(1.0)$ & $4(3.8)$ & $1(1.0)$ & $0(0)$ \\
\hline & Total before & 420 & $143(34.0)$ & $96(22.9)$ & $75(17.9)$ & $54(12.9)$ & $28(6.7)$ & $14(3.3)$ & $7(1.7)$ & $3(0.7)$ \\
\hline After steam vacuuming & Perineal area & 105 & $53(50$ & $23(21.9)$ & $13(12.4)$ & $8(7.6$ & $6(5.7)$ & $2(1.9)$ & $0(0)$ & $0(0)$ \\
\hline$(\mathrm{n}=420)$ & Hind leg & 105 & $66(62.9)$ & $26(24.8)$ & $6(5.7)$ & $6(5.7)$ & $1(1.0)$ & $0(0)$ & $0(0)$ & $0(0)$ \\
\hline & Brisket & 105 & $23(21.9)$ & 28 (26.7) & $24(22.9)$ & $21(20.0)$ & $5(4.8)$ & $4(3.8)$ & $0(0)$ & $0(0)$ \\
\hline & Shoulder & 105 & $66(62.9)$ & $25(23.8)$ & $11(10.5)$ & $3(2.9)$ & $0(0)$ & $0(0)$ & $0(0)$ & $0(0)$ \\
\hline & Total after & 420 & $208(49.5)$ & $102(24.3)$ & $54(12.9)$ & $38(9.0)$ & $12(2.9)$ & $6(1.4)$ & $0(0)$ & $0(0)$ \\
\hline
\end{tabular}

*Detection limit at $1.9 \log \mathrm{CFU} \mathrm{cm}{ }^{-2}\left(=80 \mathrm{CFU} \mathrm{cm}^{-2}\right)$. 


\section{Results}

\section{Distribution of total viable counts results from cattle carcasses before and after steam vacuuming}

Before steam vacuuming, TVC of 277 $(66.0 \%)$ samples were above the detection limit of $1.9 \log \mathrm{CFU} \mathrm{cm}{ }^{-2}$ (Table 2). At the different carcass areas (perineal area, hind leg, brisket, shoulder), the proportion of samples above the detection limit ranged from $49.5 \%$ (hind leg) to $87.6 \%$ (brisket). After steam vacuuming, TVC of 212 $(50.5 \%)$ samples were above the detection limit and the proportion of samples above the detection limit ranged from $37.1 \%$ (hind leg, shoulder) to $78.1 \%$ (brisket) at the different areas. Over all carcass areas, the majority of TVC above the detection limit were in the range of 1.9-3.0 $\log \mathrm{CFU} \mathrm{cm} \mathrm{cm}^{-2}$ (Table 2). This was the case for both areas before and after steam vacuuming.

\section{Differences between total viable counts results from cattle carcasses before and after steam vacuuming}

For evaluation of the effect of steam vacuuming, TVC from 277 samples before steam vacuuming and the corresponding 277 samples after steam vacuuming were investigated (Table 3). Overall, mean log TVC of samples before and after steam vacuuming accounted for 2.9 and $2.3 \log$ CFU $\mathrm{cm}^{-2}$, respectively. At the different carcass areas, mean log TVC of samples before steam vacuuming ranged from 2.6 to $3.1 \mathrm{log}$ $\mathrm{CFU} \mathrm{cm}{ }^{-2}$ (Table 3). Mean values from the perineal area and brisket were comparable (3.0-3.1 log CFU $\mathrm{cm}^{-2}$ ) and higher than those from the hind leg and shoulder (2.6$2.7 \log \mathrm{CFU} \mathrm{cm} \mathrm{cm}^{-2}$ ). TVC from respective areas differed significantly before and after steam vacuuming $(\mathrm{P}<0.05)$. Reductions of mean $\log$ TVC obtained by steam vacuum- ing accounted for $0.9,0.7,0.6$, and $0.4 \log$

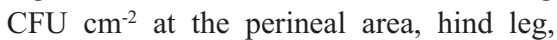
shoulder, and brisket, respectively. After steam vacuuming, mean log TVC from the perineal area, hind leg, and shoulder were comparable (2.0-2.2 $\log \mathrm{CFU} \mathrm{cm}-2)$, whereas the mean value from the brisket account-

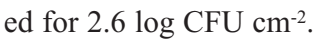

Furthermore, TVC results obtained from the different carcass areas were analyzed for three animal categories: calves, feeder cattle, and cows (Table 4). Before steam vacuuming, mean log TVC from the different areas ranged from 2.6 to $3.2 \mathrm{log}$ CFU cm${ }^{-2}$ for calves, 2.3 to $3.2 \log \mathrm{CFU} \mathrm{cm}-$ 2 for feeder cattle, and 2.3 to $3.1 \log \mathrm{CFU}$ $\mathrm{cm}^{-2}$ for cows. Highest mean values were thereby found at the perineal area (feeder cattle, cows) or at the brisket (calves). Reductions of mean $\log$ TVC at the different areas ranged from 0.4 to $0.8 \log \mathrm{CFU}$ $\mathrm{cm}^{-2}$ for calves, 0.3 to $0.8 \log \mathrm{CFU} \mathrm{cm}-2$ for feeder cattle, and 0.3 to $1.1 \log \mathrm{CFU} \mathrm{\textrm {cm } ^ { - 2 }}$ for cows. Greatest reductions of mean values were found for all animal categories at the perineal area $(\mathrm{P}<0.05)$. Reductions of mean values at the hind leg $(0.6-0.7 \log$ CFU cm $\left.\mathrm{cm}^{-2}\right)$ or at the brisket $(0.3-0.5 \log$ $\mathrm{CFU} \mathrm{cm}^{-2}$ ) were comparable between the animal categories. A less uniform picture was evident at the shoulder: Steam vacuuming reduced mean values by $0.8 \log \mathrm{CFU}$ $\mathrm{cm}^{-2}$ for calves $(\mathrm{P}<0.05), 0.5 \log \mathrm{CFU} \mathrm{cm} \mathrm{cm}^{-2}$ for feeder cattle, and $0.3 \log \mathrm{CFU} \mathrm{cm} \mathrm{cm}^{-2}$ for cows. After steam vacuuming, mean $\log$ TVC from the different areas ranged from 2.0 to $2.8 \log \mathrm{CFU} \mathrm{cm} \mathrm{cm}^{-2}$ for calves, 1.9 to $2.5 \log \mathrm{CFU} \mathrm{cm^{-2 }}$ for feeder cattle, and 2.0 to $2.2 \log \mathrm{CFU} \mathrm{cm}{ }^{-2}$ for cows.

\section{Discussion}

Manual steam vacuuming has proven to be a useful tool for application to designated carcass areas that are more likely to be

Table 3. Total viable counts results from cattle carcasses before and after steam vacuuming.

\begin{tabular}{|c|c|c|c|c|c|}
\hline & \multirow[t]{2}{*}{ Sampling area } & \multirow{2}{*}{$\begin{array}{l}\text { No of } \\
\text { samples }\end{array}$} & \multicolumn{3}{|c|}{ TVC results } \\
\hline & & & $\bar{x}$ & SD & Max \\
\hline \multirow{4}{*}{$\begin{array}{l}\text { Before steam vacuuming } \\
(\mathrm{n}=277)\end{array}$} & Perineal area & 77 & 3.09 & 0.81 & 5.19 \\
\hline & Hind leg & 52 & 2.68 & 0.66 & 4.17 \\
\hline & Brisket & 92 & 2.95 & 0.71 & 5.03 \\
\hline & Shoulder & 56 & 2.55 & 0.75 & 4.81 \\
\hline \multirow{4}{*}{$\begin{array}{l}\text { After steam vacuuming } \\
(\mathrm{n}=277)\end{array}$} & Perineal area & 77 & 2.23 & 0.72 & 4.22 \\
\hline & Hind leg & 52 & 2.03 & 0.59 & 3.92 \\
\hline & Brisket & 92 & 2.57 & 0.75 & 4.36 \\
\hline & Shoulder & 56 & 1.97 & 0.54 & 3.46 \\
\hline \multirow{4}{*}{$\begin{array}{l}\Delta \text { TVC-mean log values } \\
\text { before/after steam- vacuuming }\end{array}$} & Perineal area & & $0.86^{*}$ & & \\
\hline & Hind leg & & $0.64^{*}$ & & \\
\hline & Brisket & & $0.38 *$ & & \\
\hline & Shoulder & & $0.56^{*}$ & & \\
\hline
\end{tabular}

TVC, total viable counts; SD, standard deviation. ${ }^{\circ}$ TVC results from the untreated and the corresponding treated sample only considered when TVC before steam vacuuming $\geq$ detection limit $\left(1.9 \log \mathrm{CFU} \mathrm{cm}^{2}{ }^{2}\right) ;{ }^{\sharp} \bar{x}$ and SD, mean $\log \mathrm{CFU} \mathrm{cm}^{-2}$ and standard deviation; Max, maximum (log

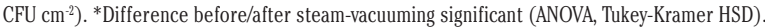

Table 4. Total viable counts results from cattle carcasses of different animal categories before and after steam vacuuming.

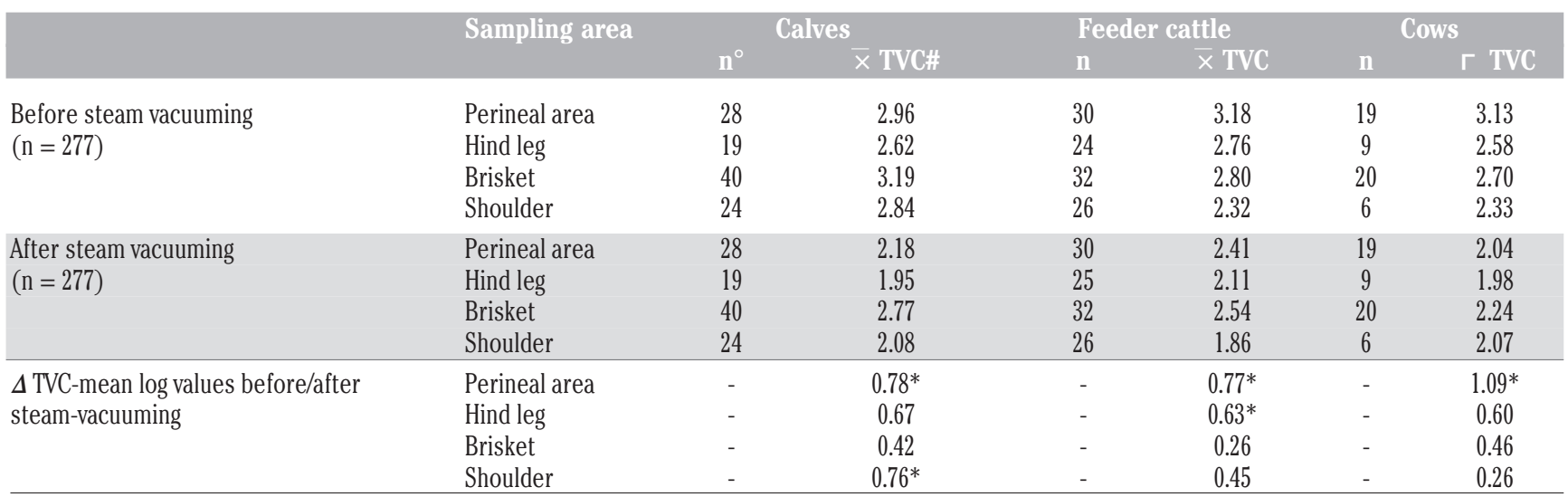

TVC, total viable counts. ${ }^{\circ}$ TVC results from the untreated and the corresponding treated sample only considered when TVC before steam vacuuming $\geq$ detection limit $\left(1.9\right.$ log $\left.\mathrm{CFU}_{\mathrm{cm}}{ }^{2}\right) ;{ }^{*} \overline{\mathrm{X}} \mathrm{TVC}, \mathrm{mean}$ log $\mathrm{CFU} \mathrm{cm}^{-2}$. *Difference before/after steam-vacuuming significant (ANOVA, Tukey-Kramer HSD). 
contaminated (Bolton et al., 2001; Huffman, 2002; Wheeler et al., 2014). The antimicrobial effect of steam-vacuuming is thereby influenced by varying framing conditions such as the skill of the operator, the exposure time, the application temperature, the treated carcass area, the point of application during processing or the contamination level of the carcasses. In particular it must be considered that most available data appraising the effect of steam vacuuming on cattle carcasses resulted from laboratory studies using inoculated samples and extrapolation to commercial practices is not warranted.

The present study evaluated the effect of a commercial steam-vacuuming system newly implemented in a cattle abattoir after slaughtering used on a daily basis. For this purpose, four different areas of cattle carcasses (perineal area, hind leg, brisket, shoulder) were examined for total viable counts (TVC) before and after the application of steam vacuuming during routine operations. Before steam vacuuming, mean TVC of the excision samples from the different carcass areas ranged from 2.6 to 3.1 $\log \mathrm{CFU} \mathrm{\textrm {cm } ^ { - 2 }}$. Based on this contamination level, steam vacuuming after carcass trimming reduced the mean values by $0.4-0.9$

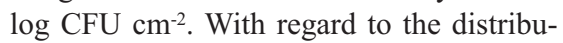
tion of TVC, steam vacuuming increased the proportion of results below $3.0 \log \mathrm{CFU}$ $\mathrm{cm}^{-2}$ from $74.8 \%(62.9-87.6 \%$ at the different carcass areas) to $86.7 \%(71.4-97.1 \%$ at the different carcass areas).

The few previous studies investigating the antimicrobial effect of steam vacuuming on naturally contaminated cattle carcasses under commercial conditions yielded comparable results (Gill and Bryant, 1997; Kochevar et al., 1997). Kochevar et al. (1997) compared the antimicrobial effect of two steam-vacuuming systems and observed no remarkable difference on preevisceration cattle carcasses. However, reductions reported by Kochevar et al. (1997) were clearly influenced by the varying cleanliness of treated carcass areas. On cattle carcasses without visible fecal contamination, TVC and coliforms were reduced on average by $0.3-0.7 \log \mathrm{CFU} \mathrm{cm}^{-}$ ${ }^{2}$, whereas average reductions on carcasses with visible fecal contamination reached

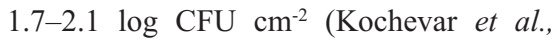
1997). In another study performed under commercial conditions (Gill and Bryant, 1997), steam vacuuming applied at different slaughter process stages and carcass areas reduced TVC, coliforms, and Escherichia coli on average by $0.2-0.8$ orders of magnitude. Using a commercial household steam cleaner (without vacuum unit) after final carcass washing, Trivedi et al., (2007) reported average reductions of TVC, coliforms, and E. coli by $0.8-1.2 \log \mathrm{CFU} \mathrm{cm}^{-}$ 2 . On the other hand, under laboratory conditions, steam vacuuming reduced several bacterial species inoculated on cattle carcass surface parts by 1.6-5.5 orders of magnitude (Castillo et al., 1999; Dorsa et al., 1996; Dorsa et al., 1996; Dorsa et al., 1997; Phebus et al., 1997).

When comparing the reductions obtained by steam vacuuming in the present study at the four different areas, mean TVC values before and after steam vacuuming differed at three areas (perineal area, hind leg, brisket, shoulder) by more than $0.5 \mathrm{log}$ CFU cm$~^{-2}$ but less than $1.0 \log \mathrm{CFU} \mathrm{cm}^{-2}$. Greatest reductions (on average by $0.9 \mathrm{log}$ $\mathrm{CFU} \mathrm{cm} \mathrm{cm}^{-2}$ ) were found for the perineal area, which was also the area with the highest contamination level before steam vacuuming (3.1 log CFU cm$~^{-2}$ ). In a recent study by Hassan et al. (2015) examining the antimicrobial effect of steam vacuuming on sheep and lamb carcasses, steam vacuuming also had the best effect on the circle around the circum anal incision, especially with regard to Enterobacteriaceae and Escherichia coli indicating more frequent fecal contamination. On the other hand, lowest reductions

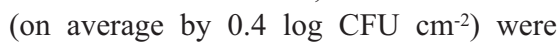
found in the present study for the brisket. Because the contamination level at the perineal area and the brisket before steam vacuuming were comparable (and higher than at the other areas), other factors such as e.g. the performance by the operators must be responsible for the lower reductions at the brisket. After steam vacuuming, the mean TVC value at the brisket $\left(2.6 \log \mathrm{CFU} \mathrm{cm}^{-}\right.$ ${ }^{2}$ ) was therefore about 0.5 orders of magnitude higher than at the other areas.

Contamination levels of carcasses from the three animal categories (calves, feeder cattle, cows) and reductions obtained by steam vacuuming for the three animal categories were generally comparable and in accordance with the findings mentioned above. However, there were some area-specific, minor differences: e.g. the different pre-treatment contamination pattern on carcasses from calves (highest contamination at the brisket), or the slightly increased reductions obtained by steam vacuuming at the perineal area of carcasses from cows (on average by $1.1 \log \mathrm{CFU} \mathrm{cm} \mathrm{cm}^{-2}$ ). Comparisons between the animal categories however showed that mean values from the respective carcass areas (before or after the application of steam vacuuming) differed by $\leq 0.5 \log \mathrm{CFU} \mathrm{cm} \mathrm{cm}^{-2}$.

\section{Conclusions}

Under commercial conditions, a steamvacuuming system newly implemented after slaughtering in a cattle abattoir and used on a daily basis reduced bacterial loads on treated carcass areas to some extent, but the decontamination effect of steam vacuuming must not be overestimated. Based on the contamination level of the examined cattle carcasses, average reductions of TVC obtained by steam vacuuming at the different areas were generally below one order of magnitude. Furthermore, decontamination treatments such as steam vacuuming always must be seen as an additional part of an integral food safety system. Decontamination treatments cannot compensate for poor hygiene practices or replace strict maintenance of good slaughter hygiene practices along with risk-based preventive measures. But provided that good manufacturing and hygiene practices are warranted during the cattle slaughter process, steam vacuuming after slaughtering can be a useful tool for further reduction of carcass contamination in small, designated areas.

\section{References}

Aymerich T, Picouet PA, Monfort JM, 2008. Decontamination technologies for meat products. Meat Sci 78:114-29.

Bolton DJ, Doherty AM, Sheridan JJ, 2001. Beef HACCP: intervention and nonintervention systems. Int $\mathrm{J}$ Food Microbiol 66:119-29.

Castillo A, Lucia LM, Goodsen KJ, Savell JW, Acuff GR, 1999. Decontamination of beef carcass surface tissue by steam vacuuming alone and combined with hot water and lactic acid sprays. J Food Protect 62:146-51.

Dorsa WJ, Cutter CN, Siragusa GR, 1996. Effectiveness of a steam-vacuum sanitizer for reducing Escherichia coli O157:H7 inoculated to beef carcass surface tissue. Lett Appl Microbiol 23:613.

Dorsa WJ, Cutter CN, Siragusa GR, 1997. Effects of acetic acid, lactic acid and trisodium phosphate on the microflora of refrigerated beef carcass surface tissue inoculated with Escherichia coli O157:H7, Listeria innocua, and Clostridium sporogenes. J Food Protect 60:619-24.

Dorsa WJ, Cutter CN, Siragusa GR, Koohmaraie M, 1996. Microbial decontamination of beef and sheep carcasses by steam, hot water spray washes, and a 
steam-vacuum sanitizer. J Food Protect 59:127-35.

EFSA/ECDC, European Food Safety Authority/European Center for Disease Prevention and Control, 2016. The European Union summary report on trends and sources of zoonoses, zoonotic agents and food-borne outbreaks in 2015. EFSA J 14:4634.

Gill CO, 2009. Effects on the microbiological condition of product of decontaminating treatments routinely applied to carcasses at beef packing plants. J Food Protect 72:1790-801.

Gill CO, Bryant J, 1997. Decontamination of carcasses by vacuum-hot water cleaning and steam pasteurizing during routine operations at a beef packing plant. Meat Sci 47:267-76.

Greig JD, Waddell L, Wilhelm B, Wilkins W, Bucher O, Parker S, Rajić A, 2012. Efficacy of primary processing interventions on contamination of beef carcasses with Escherichia coli: a systematic review-meta-analysis. Food Control 27:385-97.
Hassan AA, Skjerve E, Bergh C, Nesbakken T, 2015. Microbial effect of steam vacuum pasteurisation implemented after slaughtering and dressing of sheep and lamb. Meat Sci 99:32-7.

Huffman RD, 2002. Current and future technologies for the decontamination of carcasses and fresh meat. Meat Sci 62:285-94.

Hugas M, Tsigarida E, 2008. Pros and cons of carcass decontamination: the role of the European Food Safety Authority. Meat Sci 78:43-52.

Kochevar SL, Sofos JN, Bolin RR, Reagan JO, Smith GC, 1997. Steam vacuuming as a pre-evisceration intervention to decontaminate beef carcasses. J Food Protect 60:107-13.

Koohmaraie M, Arthur TM, Bosilevac JM, Guerini M, Shackelford SD, Wheeler TL, 2005. Post-harvest interventions to reduce/eliminate pathogens in beef. Meat Sci 71:79-91.

Loretz M, Stephan R, Zweifel C, 2011. Antibacterial activity of decontamination treatments for cattle hides and beef carcasses. Food Control 22:347-59.

Phebus RK, Nutsch AL, Schafer DE, Wilson RC, Riemann MJ, Leising JD, Kastner CL, Wolf JR, Prasai RK, 1997. Comparison of steam pasteurization and other methods for reduction of pathogens on surfaces of freshly slaughtered beef. J Food Protect 60:476-84.

Ropkins K, Beck AJ, 2000. Evaluation of worldwide approaches to the use of HACCP to control food safety. Trends Food Sci Technol 11:10-21.

Sofos JN, 2008. Challenges to meat safety in the 21st century. Meat Sci 78:3-13.

Trivedi S, Reynolds AE, Chen J, 2007. Use of a commercial household steam cleaning system to decontaminate beef and hog carcasses processed by four small or very small meat processing plants in Georgia. J Food Protect 70:635-40.

Wheeler TL, Kalchayanand N, Bosilevac JM. 2014. Pre- and post-harvest interventions to reduce pathogen contamination in the U.S. beef industry. Meat Sci 98:372-82. 